\title{
Enhancing attraction of the vector mosquito Aedes albopictus by using a novel synthetic odorant blend
}

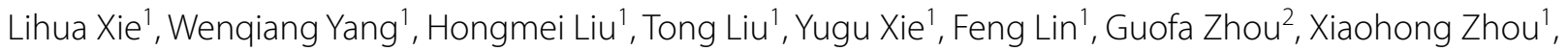
Kun $\mathrm{Wu}^{1}$, Jinbao $\mathrm{Gu}^{1}$, Guiyun Yan ${ }^{2}$ and Xiao-Guang Chen ${ }^{{ }^{*}}$

\begin{abstract}
Background: The Asian tiger mosquito, Aedes albopictus, an increasingly relevant arboviral vector, has spread worldwide. However, currently available tools are limited in terms of effective monitoring of vector populations and accurate determination of the extent of viral transmission, especially before and during outbreaks. Therefore, it is essential to develop novel monitoring and surveillance tools, particularly those that target adult mosquitoes and enhance the trapping efficiency for Ae. albopictus.
\end{abstract}

Methods: A variety of human body odorants associated with different types of mosquito olfactory receptors were selected, and their attractiveness to Ae. albopictus was tested by a four-arm olfactometer. The optimal compatibility and proportion of the odorants, Mix-5, was observed via orthogonal design analyses. The attractiveness of Mix-5 to Ae. albopictus in the laboratory was assessed using Mosq-ovitraps and Electric Mosquito Killers. In the field, the effectiveness of generic BG-Lure, Mix-5 and a control treatment was compared with a baited Biogents Sentinel trap (BGS-trap) using a Latin square design.

Results: In the olfactometer experiments, the attractiveness of the selected candidate compounds at varying dilutions was poor when the individual compounds were used alone. The optimal combination, Mix-5, was generated based on orthogonal design analyses. In the laboratory, the average numbers of female Ae. albopictus mosquitoes attracted by the synthetic odorant blend Mix-5 were 27.00 and 27.50, compared with 12.00 and 14.83 for the control, when using Mosq-ovitraps and Electric Mosquito Killers, respectively. In the field, the average number of Ae. albopictus female mosquitoes trapped by Mix-5 was 9.67 females/trap, whereas the average numbers for BG-Lure and the control were 7.78 and 4.47 , respectively. The lure also played an important role in attracting Culex quinquefasciatus mosquitoes, and the average numbers of $C x$. quinquefasciatus female mosquitoes attracted by Mix-5, BG-Lure and the control were 18.78, 25.11 and 12.22, respectively.

Conclusions: A human odor-based bait blend was developed and exhibited enhanced effectiveness at attracting Ae. albopictus This blend can be used to monitor and trap dengue vector mosquitoes in Chinese cities.

Keywords: Olfaction, Host-seeking behavior, Attractive odor blend, Orthogonal design, Mosquito traps, Aedes albopictus

\footnotetext{
*Correspondence: xgchen2001@hotmail.com

1 Department of Pathogen Biology, Guangdong Provincial Key Laboratory of Tropical Disease Research, School of Public Health, Southern Medical University, Guangzhou, China

Full list of author information is available at the end of the article
} 


\section{Background}

Vector-borne diseases pose a substantial and everincreasing threat to public health and economies. The Asian tiger mosquito, Aedes albopictus, is a vector of several infectious diseases including dengue, chikungunya and Zika fevers, and is spreading throughout the world [1]. With no effective antiviral drugs or vaccines available for major Aedes-transmitted infectious diseases except yellow fever, the only viable method to prevent and control these diseases is control of the mosquito population. Aedes albopictus is a diurnally active species that exhibits relatively low sensitivity to light. The Biogents Sentinel (BGS) trap equipped with the standard BG-Lure (lactic acid, ammonia and hexanoic acid) [2, 3] and/or synergized with $\mathrm{CO}_{2}$ was initially designed for surveillance of the yellow fever mosquito, Aedes aegypti [3]. This tool has proven to be effective at trapping adult Aedes mosquitoes $[4,5]$. However, mosquitoes use a variety of olfactory signals to locate the host, and the odor of human hosts is a mixture of many volatile compounds from the breath, skin, sweat and associated microbiota; therefore, BGLure may not be the most efficient attractant [6-8]. Furthermore, other studies have shown that in the absence of $\mathrm{CO}_{2}$, the $\mathrm{BG}$-Lure cartridge alone cannot increase the capture of mosquitoes relative to an unbaited trap, indicating that $\mathrm{CO}_{2}$ is an essential addition for attracting $A e$. albopictus $[4,9]$.

Host-seeking in mosquitoes is mediated primarily by olfaction. Many synthetic odor blends have been developed to survey and control mosquito vectors [10-12]. To enhance trapping efficiency, different chemoreceptors in receptor neurons, including odorant receptors (ORs), ionotropic receptors (IRs) and gustatory receptors (GRs), need to be activated. Intriguingly, cyclopentanone $\left(\mathrm{C}_{5} \mathrm{H}_{8} \mathrm{O}\right)$ activates the cpA $\mathrm{CO}_{2}$ receptor neuron on the maxillary palp of mosquitoes, suggesting that this molecule may be a potential $\mathrm{CO}_{2}$ substitute for mosquito surveillance [13]. A previous study found that cyclopentanone was less effective than $\mathrm{CO}_{2}$ as a mosquito attractant [14]. However, to our knowledge, no study has been conducted to assess whether the attractiveness of a blend can be enhanced with the incorporation of cyclopentanone.

A number of studies have been conducted to test the response of female mosquitoes to different odors in the laboratory and in field settings. Among the odors tested, 3-methyl-1-butanol, 6-methyl-5-hepten-2-one, hexanoic acid, 1-octen-3-ol, lactic acid and ammonia have been shown to attract Aedes female mosquitoes with fresh and/or incubated sweat or with incubated sweat liquid $[2,6,8,13,15-20]$. The most attractive blend or optimal combination of attractants at different concentrations to Ae. albopictus remains to be identified.
In this study, we selected seven odors that interacted with different classes of chemoreceptors: lactic acid, ammonia and hexanoic acid activate IRs in Drosophila, and many of these IRs are highly conserved in insects [21-23], while 3-methyl-1-butanol, cyclopentanone, 6-methyl-5-hepten-2-one (sulcatone) and 1-octen-3-ol activate ORs [24-26]. Additionally, cyclopentanone activates the cpA $\mathrm{CO}_{2}$ receptor neuron, which, in Aedes mosquitoes, harbors gustatory receptor 3 (GR3) [27]. The aim is to develop an attractive odor blend with enhanced attractiveness to improve the surveillance efficacy for $A e$. albopictus mosquitoes.

\section{Methods \\ Mosquitoes}

The Ae. albopictus strain was obtained from the Center for Disease Prevention and Control (CDC), Guangdong Province, China. Mosquitoes were maintained under controlled conditions with a light:dark ratio of $14: 10$ $\mathrm{h}$ at a mean temperature of $27 \pm 1{ }^{\circ} \mathrm{C}$ and a mean relative humidity ( $\mathrm{RH})$ of $75 \pm 5 \%$. The larvae were fed with fish food, and the adults were maintained on a $10 \%$ sugar solution. The mosquitoes had no prior access to a blood meal but had the opportunity to mate before the experiments.

\section{Compounds used to produce odorant blends}

Lactic acid, hexanoic acid, 3-methyl-1-butanol, cyclopentanone, 1-octen-3-ol and 6-methyl-5-hepten-2-one were purchased from Sigma-Aldrich (St. Louis, MO, USA). Ammonia was purchased from Merck (Billerica, MA, USA). The purities and sources of the chemicals used in this study are listed in Additional file 1: Table S1. Details regarding the molecular structure and activated receptor of each odorant are shown in Additional file 2: Table S2.

\section{Olfactometer bioassays}

Y-tube, 3-port and 4-port olfactometers are available for similar experiments [28-30]. The Y-tube olfactometer design is good for testing one compound against a control [28], while the 3-port design is good for testing two compounds against a control [29]. Since we planned to test at least 3 concentrations of the same compound against a control, we used a modified version of the olfactometer originally described by Pettersson [30]. Briefly, the fourarm arena olfactometer (Shanghai Yuming Instrument Co., Shanghai, China) consisted of a large Perspex box $(60 \mathrm{~cm} \times 60 \mathrm{~cm} \times 60 \mathrm{~mm})$ connected to 4 inlet ports and 1 outlet port (Fig. 1). This olfactometer was composed of a star-shaped arena consisting of four regions and a neutral central zone that served as a mosquito holding space. The odor sources were contained in the glass arms, which were connected to holes on the sides of the olfactometer 


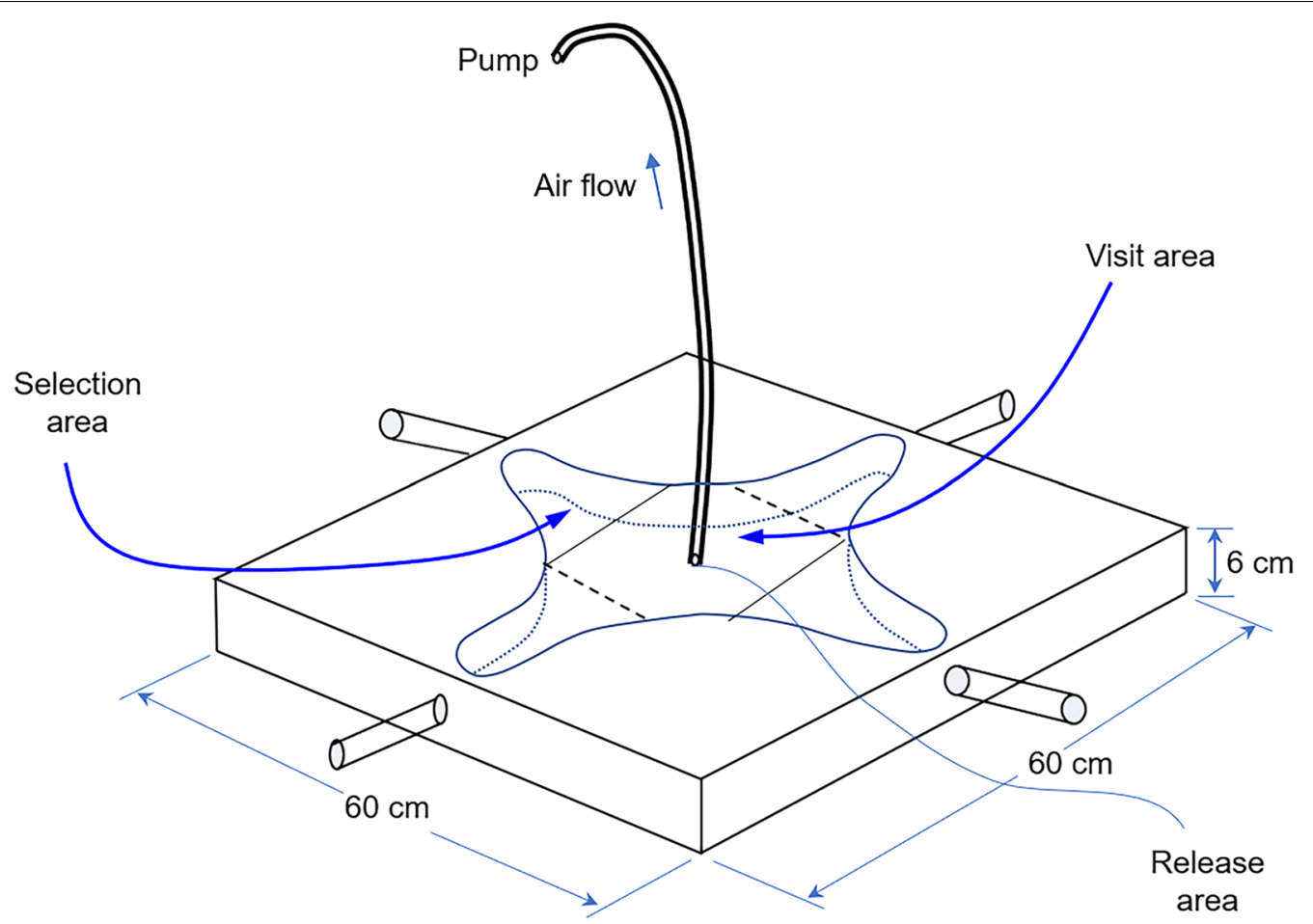

Fig. 1 Pattern diagram of four-arm olfactometer (modified from Pettersson [30])

corresponding to the four regions within the olfactometer (Fig. 1). In this study, one arm served as the control, and the remaining arms were used as treatments. Mosquitoes were released in the middle (Fig. 1). If a mosquito remained in the central area (visit area in Fig. 1) during the experiments, the mosquito was considered to not be attracted by any odor. In contrast, if a mosquito moved and stayed in any of the 'selection' areas, the mosquito was considered to be attracted by an odor.

We placed $100 \mu \mathrm{l}$ of the test stimulus on a $1-\mathrm{cm}^{2}$ piece of filter paper, allowed $30 \mathrm{~s}$ for the solvent to evaporate, and then placed the paper in a treatment arm. For the control arms, $100 \mu \mathrm{l}$ of hexane or water was applied to the filter paper. For each trial, 50 non-blood-fed 5-7-day-old female mosquitoes were used. Mosquitoes were released 30 min before odor stimulus was added, and the vacuum was initiated; the experiment was performed for approximately $15 \mathrm{~min}$. The air flow rate was approximately 900 $\mathrm{ml} / \mathrm{min}$. The number of mosquitoes was counted in each selection area, and the corresponding odor was recorded. This process was repeated 6-10 times for each of the concentration.

\section{Screening of the most attractive odorant blends}

The experiments were carried out under an ambient temperature of $26-28{ }^{\circ} \mathrm{C}$ and humidity of $65-85 \%$ in a $6 \times 4 \times 3 \mathrm{~m}$ laboratory. Approximately 50 female mosquitoes at 3-8 days post-eclosion and starved for $12 \mathrm{~h}$ were used for each test. The odor mixture was dispersed on 2-cm-diameter circular filter papers, which were placed in Mosq-ovitraps in the two diagonals of a Mongolian yurt $(2.0 \times 1.8 \mathrm{~m})$ [31]. Each experiment consisted of an experimental group and a control group; the experiments were started at 17:00 $\mathrm{h}$ and sustained for 24 $\mathrm{h}$. According to the olfactometer results and the composition of artificial sweat (EN 1811:1998): ammonia at $1 \%$ and lactic acid at $0.1 \%$ were used. Another five optimal combinations of odors at different concentrations was determined using an orthogonal design, i.e. each concentration was repeated 4 times (Additional file 3: Table S3). To increase the power of the experiments, the whole orthogonal experiment was repeated twice rather than once, i.e. each concentration was repeated 8 times. Mosq-ovitraps were cleaned with 30\% methanol solution before being reused.

\section{Analysis of the effect of the most attractive odorant blends Laboratory experiments}

We tested our optimized combination in the Mongolian yurt using Mosq-ovitraps and Electric Mosquito Killer provided by Shunde Douhe Electronic Technology Co., Ltd. (Guangdong China). This process was repeated 6 times for each trap. 


\section{Field study}

The attractiveness of the optimal blend obtained from the orthogonal experiment was further evaluated in the field against other currently used blends. Field studies were carried out from May 2016 to November 2017 on the campus of Southern Medical University $\left(23^{\circ} 19^{\prime} 0^{\prime \prime} \mathrm{N}\right.$, $113^{\circ} 34^{\prime} 0^{\prime \prime} \mathrm{E}, 31 \mathrm{~m}$ above sea level), Guangzhou, China. Three study sites were chosen to represent a residential area, a park and a parterre. All the sites were examined for potential mosquito larval habitats before the experiments were conducted. We used a Latin square experimental design of days $\times$ sites $\times$ lures. A BG-Sentinel 2 trap (Biogents AG, Regensburg, Germany) was used as the "gold standard" trap [32,33] for evaluation of the effectiveness of different attractants against Aedes mosquitoes.

We tested three types of attractants: (i) the BG-Lure, which consists of lactic acid, ammonia and caproic acid (hexanoic acid) [3]; (ii) the optimal blend obtained from the laboratory tests described above, which was dispersed by soaking nylon fabric as described by Okumu et al. [34]; and (iii) a blank control. The nylon strips were soaked in $1 \mathrm{ml}$ of each chemical constituent at the optimal concentration for each attractant. The traps were placed at least $50 \mathrm{~m}$ apart and cleaned with $30 \%$ methanol solution before being reused. The Latin square design experiments were replicated three times. Mosquitoes collected from the traps were frozen and identified morphologically under a stereomicroscope using taxonomy keys [35].

\section{Statistical analysis}

Differences among the mosquitoes captured in different arms of the olfactometer were compared using one-way ANOVA. In the Mongolian yurt experiments, data were analyzed using one-way ANOVA to screen the most attractive odorant blends, while a t-test was used to compare the optimized combination with control treatment in different type of trap. In the field study, the effects of the three types of attractant were tested while controlling for the variability among the three different sites (in this case, the Latin square number) and the three different trapping periods. The GLM procedure was performed using the number of female Ae. albopictus adults and female Culex quinquefasciatus mosquitoes collected in each trap as dependent variables and the attractants (BGLure, control and the optimal Mix-5) and the sites (of the trap) as fixed independent variables, and test dates were used as covariables. Multiple comparison procedures (Tukey's HSD tests) were also performed to test significant differences in the number of mosquitoes caught among different treatments. Statistical analysis was performed using SPSS v.20.0 statistical software (IBM,
Armonk, NY, USA). Prism v.6 (GraphPad Software, Inc., San Diego, USA) was used to plot the figures.

\section{Results \\ Odor stimuli in four-arm olfactometer experiments}

Among the 7 candidate odors tested, there were no significant differences among the five different concentrations of ammonia and four different concentrations of L-lactic acid (Fig. 2, Table 1). Hexanoic acid at $10 \%\left(F_{(4,45)}=5.03, \quad P=0.002\right)$, 3-methyl-1-butanol at $0.1 \%\left(F_{(4,45)}=6.52, P=0.0003\right), 1$-octen-3-ol at $10 \%\left(F_{(4,}\right.$ $\left.{ }_{45}=9.46, P<0.0001\right)$ and sulcatone at $0.1 \%$ and $0.001 \%$ $\left(F_{(4,45)}=8.06, \quad P<0.0001\right)$ attracted significantly higher numbers of mosquitoes than the control treatment and other concentrations of the same compound. For cyclopentanone in the range of $0.01 \%$ to $10 \%\left(F_{(4,45)}=9.15\right.$, $P<0.0001)$, the attractiveness increased with an increase in concentration (Fig. 2, Table 1).

\section{Determination of the optimal combination}

A mixture of hexanoic acid at 0.1\%, 3-methyl-1-butanol at $1 \%$ and cyclopentanone at $1 \%$ (Table 2, Fig. 3 ) attracted the highest number of mosquitoes. The blend termed Mix-5, which contained ammonia (1\%), lactic acid (0.1\%), hexanoic acid (0.1\%), 3-methyl-1-butanol (1\%) and cyclopentanone (1\%), was the most potent synthetic attractant for Ae. albopictus. As the addition of 1-octen-3-ol and sulcatone to Mix-5 did not significantly increase mosquito catches (Table $2, P>0.05$ ), these compounds were excluded from the optimal mixture (Additional file 4: Figure S1).

\section{Effect of Mix-5 on mosquito catches in two types of mosquito traps}

The average number of mosquitoes attracted by Mix- 5 with Mosq-ovitraps was $27.00 \pm 3.07$, compared to $12.00 \pm 3.14$ for the control $\left(t_{(10)}=3.45, \quad P=0.006\right)$ (Fig. 4a).

The average number of mosquitoes attracted by Mix- 5 was $27.50 \pm 1.63$ with the use of Electric Mosquito Killers, compared to $14.83 \pm 1.00$ for the control $\left(t_{(10)}=6.67\right.$, $P<0.0001$ ) (Fig. 4b).

\section{Field study}

A total of 1595 adult mosquitoes were collected during the study period. They consisted of 358 Ae. albopictus (197 females and 161 males), 1234 Cx. quinquefasciatus (505 females and 729 males) and 3 female Armigeres subalbtus mosquitoes. In total, 63 (40 females and 23 males, $17.60 \%), 164$ (70 females and 94 males, $45.80 \%)$ and 131 (87 females and 44 males, $36.60 \%$ ) Ae. albopictus mosquitoes were captured by traps baited with the control, BGLure and Mix-5, respectively (Table 3). The number of $A e$. 

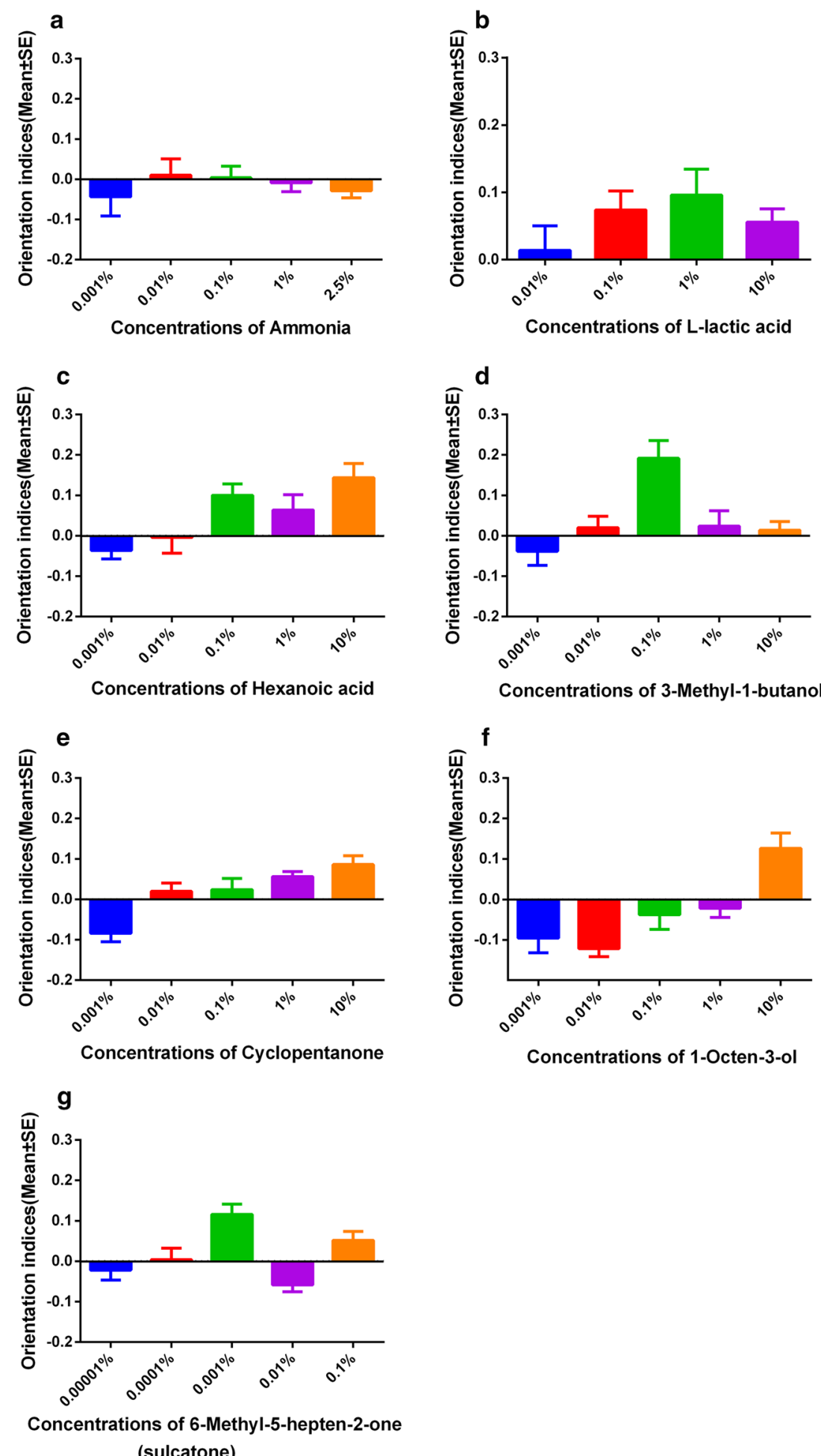

Fig. 2 Comparison of the attractancies exhibited by different concentrations of each compound against female Aedes albopictus mosquitoes. a Ammonia. b L-Lactic acid. c Hexanoic acid. d 3-Methyl-1-butanol. e Cyclopentanone. f 1-Octen-3-ol. g 6-Methyl-5-hepten-2-one. Orientation index $=(\mathrm{Nt}-\mathrm{Nc}) / T$, where $\mathrm{Nt}$ is the number of mosquitoes trapped in the treatment chamber, $\mathrm{Nc}$ is the number of mosquitoes trapped in the control chamber and $\mathrm{T}$ is the total number of test mosquitoes. Bars represent the means $\pm \mathrm{SE}(n=6-10)$ 
Table 1 Flight orientation of female Aedes albopictus responses to various concentrations of selected compounds

\begin{tabular}{|c|c|c|c|}
\hline Tested odorant & $\begin{array}{l}\text { Concentration } \\
\text { tested (\%) }\end{array}$ & $\begin{array}{l}\text { Orientation } \\
\text { indices } \\
\text { (mean } \pm \text { SE) }\end{array}$ & $n$ \\
\hline \multirow[t]{4}{*}{ L-Lactic acid } & 10 & $0.06 \pm 0.02^{\mathrm{a}}$ & 10 \\
\hline & 1 & $0.10 \pm 0.04^{\mathrm{a}}$ & 10 \\
\hline & 0.10 & $0.07 \pm 0.03^{\mathrm{a}}$ & 10 \\
\hline & 0.01 & $0.01 \pm 0.04^{\mathrm{a}}$ & 10 \\
\hline \multirow[t]{5}{*}{ Ammonia solution $\left(\mathrm{NH}_{3} \cdot \mathrm{H}_{2} \mathrm{O}\right)$} & 2.50 & $-0.01 \pm 0.02^{\mathrm{a}}$ & 6 \\
\hline & 1 & $-0.01 \pm 0.02^{\mathrm{a}}$ & 6 \\
\hline & 0.1 & $0.01 \pm 0.03^{\mathrm{a}}$ & 6 \\
\hline & 0.01 & $0.01 \pm 0.04^{\mathrm{a}}$ & 6 \\
\hline & 0.001 & $-0.04 \pm 0.05^{\mathrm{a}}$ & 6 \\
\hline \multirow[t]{5}{*}{ Hexanoic acid } & 10 & $0.14 \pm 0.04^{\mathrm{ab}}$ & 10 \\
\hline & 1 & $0.06 \pm 0.04^{\mathrm{abcd}}$ & 10 \\
\hline & 0.1 & $0.10 \pm 0.03^{\mathrm{abc}}$ & 10 \\
\hline & 0.01 & $-0.00 \pm 0.04^{b c d}$ & 10 \\
\hline & 0.001 & $-0.04 \pm 0.02^{\mathrm{cd}}$ & 10 \\
\hline \multirow[t]{5}{*}{ 3-Methyl-1-butanol } & 10 & $0.01 \pm 0.02^{\mathrm{a}}$ & 10 \\
\hline & 1 & $0.02 \pm 0.04^{\mathrm{a}}$ & 10 \\
\hline & 0.1 & $0.19 \pm 0.04^{b}$ & 10 \\
\hline & 0.01 & $0.02 \pm 0.03^{\mathrm{a}}$ & 10 \\
\hline & 0.001 & $-0.04 \pm 0.04^{\mathrm{a}}$ & 10 \\
\hline \multirow[t]{5}{*}{ Cyclopentanone } & 10 & $0.09 \pm 0.02^{\mathrm{a}}$ & 10 \\
\hline & 1 & $0.06 \pm 0.01^{\mathrm{a}}$ & 10 \\
\hline & 0.1 & $0.02 \pm 0.03^{\mathrm{a}}$ & 10 \\
\hline & 0.01 & $0.02 \pm 0.02^{\mathrm{a}}$ & 10 \\
\hline & 0.001 & $-0.08 \pm 0.02^{b}$ & 10 \\
\hline \multirow[t]{5}{*}{ 1-octen-3-ol } & 10 & $0.13 \pm 0.04^{\mathrm{a}}$ & 10 \\
\hline & 1 & $-0.02 \pm 0.02^{b}$ & 10 \\
\hline & 0.1 & $-0.04 \pm 0.04^{b}$ & 10 \\
\hline & 0.01 & $0.12 \pm 0.02^{b}$ & 10 \\
\hline & 0.001 & $-0.10 \pm 0.04^{b}$ & 10 \\
\hline \multirow[t]{5}{*}{ Sulcatone } & 0.1 & $0.05 \pm 0.02^{\text {acde }}$ & 10 \\
\hline & 0.01 & $-0.06 \pm 0.02^{\text {bde }}$ & 10 \\
\hline & 0.001 & $0.12 \pm 0.03^{\mathrm{ac}}$ & 10 \\
\hline & 0.0001 & $0.00 \pm 0.03^{\text {abde }}$ & 10 \\
\hline & 0.00001 & $-0.02 \pm 0.02^{\text {abde }}$ & 10 \\
\hline
\end{tabular}

Note: Means for different concentration for the same compound indicated with same superscript letter represent no significant difference (Tukey's HSD post-hoc test following a one-way ANOVA)

albopictus mosquitoes caught varied significantly among the three types of lures (Fig. 5a, GLM; $F_{(2,27)}=5.49$, $P=0.017$ for females). In addition, the number of female Ae. albopictus mosquitoes varied significantly at different locations $\left(\mathrm{GLM} ; F_{(2,27)}=4.33, P=0.03\right.$ for females), but there was no difference among the days of trap deployment $\left(\mathrm{GLM} ; F_{(8,27)}=1.95, P=0.132\right.$ for females).

For Cx. quinquefasciatus, 318 (110 females and 208 males, $25.77 \%$ ), 589 (226 females and 363 males, $47.73 \%$ )
Table 2 The analysis of individual odor effect $\left(R^{2}=0.914\right.$, adjusted $R^{2}=0.833$ )

\begin{tabular}{|c|c|c|c|c|c|}
\hline Source & $\begin{array}{l}\text { Type III } \\
\text { sum of } \\
\text { squares }\end{array}$ & $d f$ & Mean square & $F$-value & $P$-value \\
\hline Corrected model & 8043.22 & 15 & 536.22 & 11.34 & $<0.0001$ \\
\hline Intercept & 1001.28 & 1 & 1001.28 & 21.18 & $<0.0001$ \\
\hline Hexanoic acid & 6385.09 & 3 & 2128.37 & 45.02 & $<0.0001$ \\
\hline 3-methyl-1-butanol & 884.84 & 3 & 294.95 & 6.24 & 0.005 \\
\hline 1-octen-3-ol & 155.59 & 3 & 51.87 & 1.10 & 0.379 \\
\hline Sulcatone & 118.34 & 3 & 39.45 & .83 & 0.494 \\
\hline Cyclopentanone & 499.34 & 3 & 166.45 & 3.52 & 0.039 \\
\hline Error & 756.50 & 16 & 47.28 & & \\
\hline Total & 9801.00 & 32 & & & \\
\hline Corrected total & 8799.72 & 31 & & & \\
\hline
\end{tabular}

Abbreviation: $\mathrm{df}$, degrees of freedom

and 327 (169 females and 158 males, 26.50\%) mosquitoes were captured in the control, BG-Lure and Mix-5 traps, respectively. Table 3 shows the numbers of mosquitoes collected in the traps baited with the three different attractants in the field. The number of $C x$. quinquefasciatus mosquitoes caught was not significantly different among the three types of lures (Fig. 5b, GLM; $F_{(2,27)}=2.61, P=0.109$ for females) but was significantly different among the different locations (GLM; $F_{(2,27)}=10.03, P=0.002$ for females) and different days $\left(\mathrm{GLM} ; F_{(8,27)}=6.42, P=0.001\right.$ for females)

\section{Discussion}

Natural olfactory stimuli are typically mixtures of chemical constituents, and the identities, concentrations and ratios of these constituents are important for many odormediated behaviors. Different odors exhibit varying abilities to elicit behavioral responses. Our research focused on developing a synthetic odor blend to improve the efficacy of trapping Ae. albopictus.

Ammonia, lactic acid and carboxylic acid synergistically affect the host-seeking behavior of Anopheles gambiae (sensu stricto) [2]. Kröckel et al. [3] showed that lactic acid, ammonia and hexanoic acid at a fixed ratio attracts a large number of adult Ae. aegypti mosquitoes. A recent study demonstrated that hexanoic acid is a superior odor bait for Ae. aegypti compared to the commercially available BG-Lure [36]. Our results indicated that among the five concentrations of hexanoic acid tested, $10 \%$ was the most effective for attracting Ae. albopictus. In our study, cyclopentanone at high dosages ( $1 \%$ or $10 \%)$ attracted large numbers of mosquitoes. This result is in agreement with findings reported by Tauxe et al. [13] that cyclopentanone at a $20 \%$ concentration collected more 

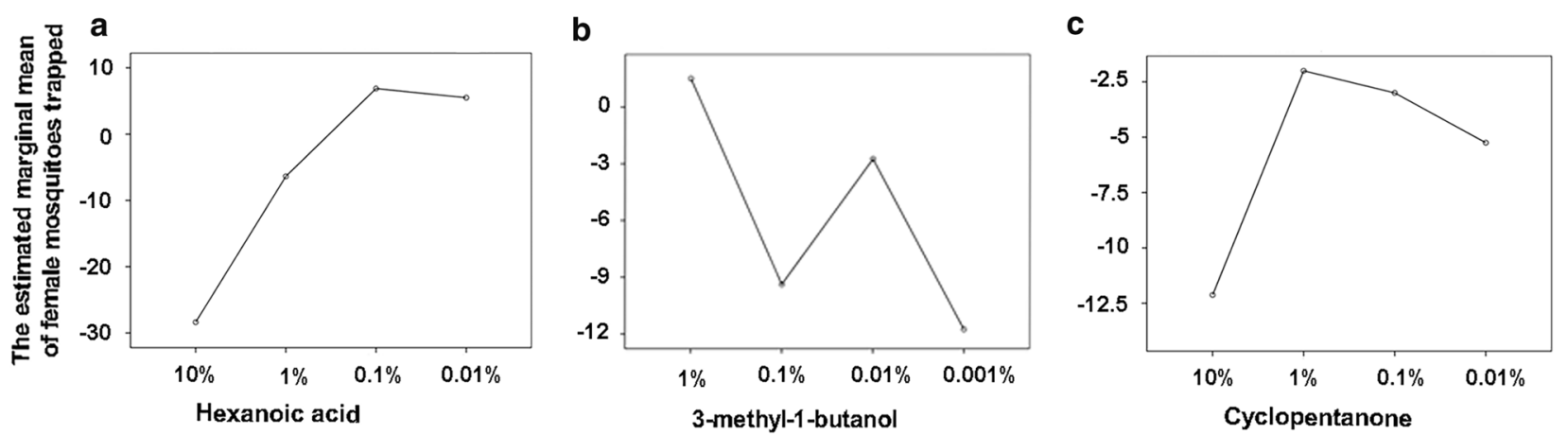

Fig. 3 The estimated marginal means of compounds in Mix-5. a Hexanoic acid. b 3-Methyl-1-butanol. c Cyclopentanone
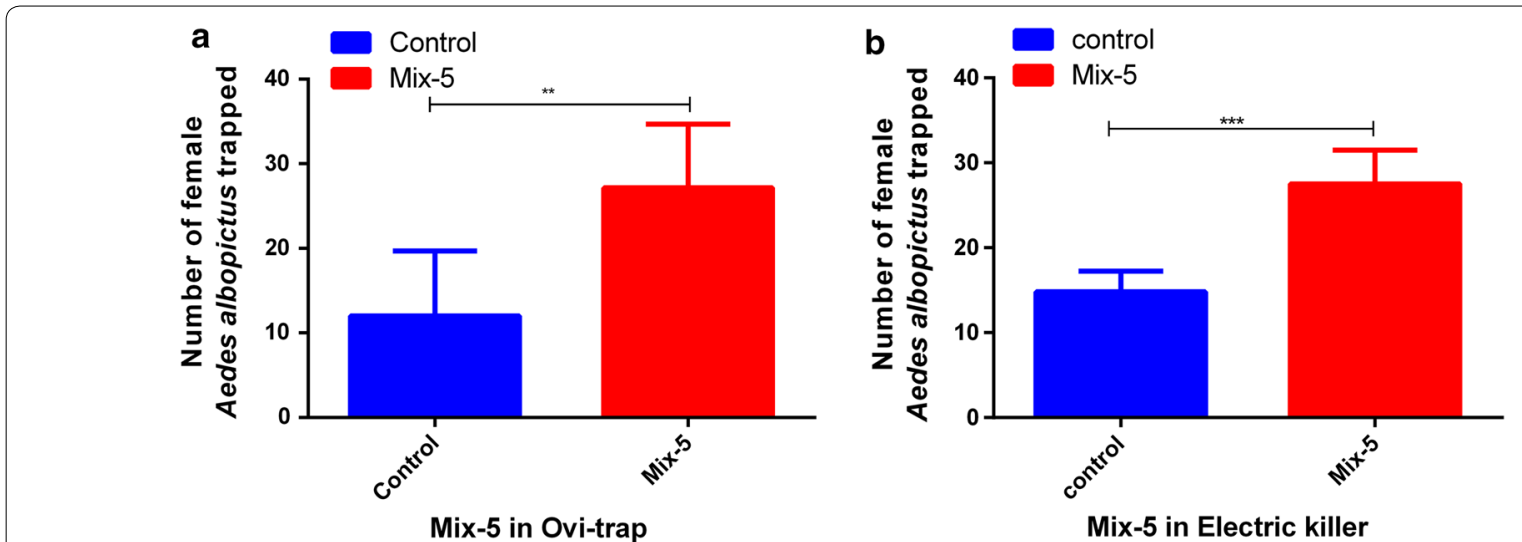

Fig. 4 Comparison of attractancy against female Aedes albopictus mosquitoes. a Mean catches by Mosq-ovitrap. $\mathbf{b}$ Mean catches by electric mosquito killer. Bars represent the means $\pm \mathrm{SE}(n=6) .{ }^{*} P<0.05,{ }^{* *} P<0.01,{ }^{* * *} P<0.001$

Table 3 Mosquitoes collected in the traps baited with three different attractants in the field

\begin{tabular}{llllll}
\hline Bait & Species & Sex & Total & Mean \pm SE & $n$ \\
\hline Control & Aedes albopictus & Female & 40 & $4.44 \pm 1.13^{\mathrm{a}}$ & 9 \\
& & Male & 23 & $2.56 \pm 1.67^{\mathrm{a}}$ & 9 \\
& \multirow{3}{*}{ Culex quinquefasciatus } & Female & 110 & $12.22 \pm 6.75^{\mathrm{b}}$ & 9 \\
& & Male & 208 & $23.11 \pm 6.50^{\mathrm{b}}$ & 9 \\
\multirow{4}{*}{ Mix-5 } & Aedes albopictus & Female & 87 & $9.67 \pm 1.13^{\mathrm{b}}$ & 9 \\
& & Male & 44 & $4.89 \pm 1.67^{\mathrm{a}}$ & 9 \\
& \multirow{4}{*}{ Culex quinquefasciatus } & Female & 169 & $18.78 \pm 4.0^{\mathrm{b}}$ & 9 \\
& & Male & 158 & $17.56 \pm 6.50^{\mathrm{b}}$ & 9 \\
& \multirow{3}{*}{ Aedes albopictus } & Female & 70 & $7.78 \pm 1.13^{\mathrm{a}}$ & 9 \\
& & Male & 94 & $10.44 \pm 1.67^{\mathrm{b}}$ & 9 \\
& \multirow{2}{*}{ Culex quinquefasciatus } & Female & 226 & $25.11 \pm 4.0^{\mathrm{b}}$ & 9 \\
& & Male & 363 & $40.33 \pm 6.50^{\mathrm{b}}$ & 9 \\
\hline
\end{tabular}

Note: The same superscript letter indicates a non-significant difference
Cx. quinquefasciatus mosquitoes than $\mathrm{CO}_{2}$-baited traps. Notably, 3-methyl-1-butanol at $0.001 \%$ significantly facilitated the trapping of Anopheles mosquitoes in the field [37]. Our results showed that female Ae. albopictus mosquitoes are attracted by $0.1 \%$ 3-methyl-1-butanol in the laboratory. We speculate that different mosquito species or experimental conditions may account for this result, which warrants further investigation.

In one previous study, 6-methyl-5-hepten-2-one was found to be a weak attractant to Ae. aegypti [38]. In contrast, another study suggested that inhibitory effects occur at low concentrations of 6-methyl-5-hepten-2-one [39]. Our study found that 6-methyl-5-hepten-2-one attracted mosquitoes at concentrations of $0.001 \%$ and $0.1 \%$ but reduced attractiveness at other concentrations. These results suggest: (i) mixtures of odorants exhibited improved attractiveness to mosquitoes relative to single 

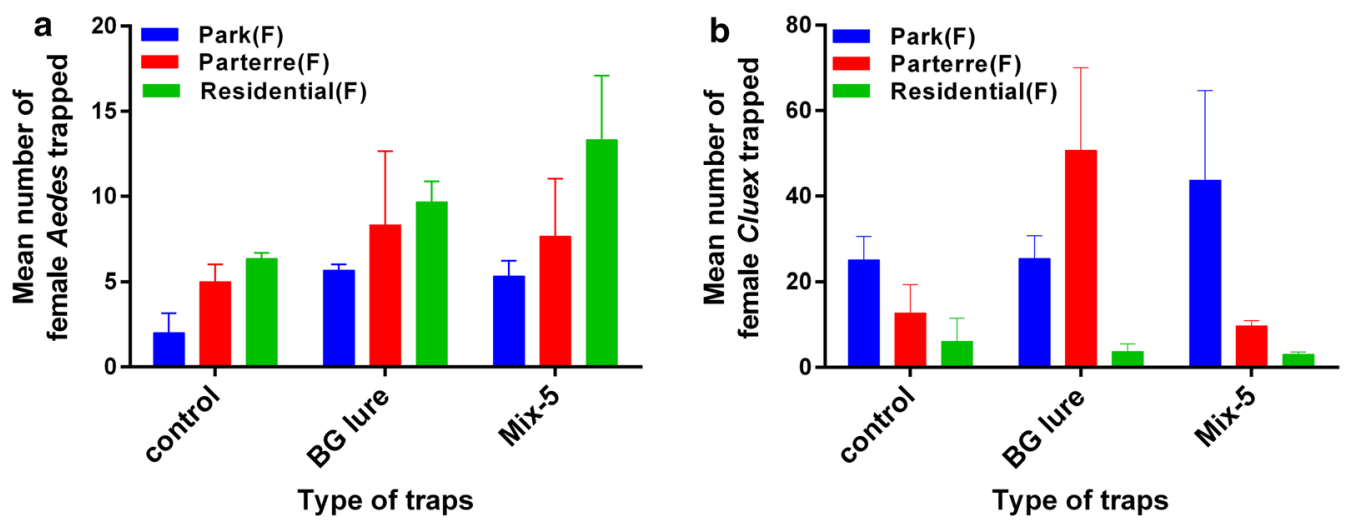

Fig. 5 Female mosquitoes collected in the traps baited with three different attractants in the field. a Aedes albopictus. b Culex quinquefasciatus. Bars represent the means $\pm \operatorname{SE}(n=9)$

odorants; and (ii) the odor mixtures work in a manner that is largely dependent on both the proportion and dilution of the ingredient. Our findings are consistent with the synergism and combinatorial coding for mixture perception reported for Drosophila [40].

In the field experiments, our results were consistent with previous investigations that showed BG-Sentinel traps were efficient tools for monitoring both Aedes and Culex mosquitoes [41]. Notably, the field evaluations demonstrated that Mix-5 was more attractive than BGLure to Ae. albopictus females, but not $C x$ quinquefasciatus female mosquitoes. The use of Mix-5 in combination with BG-Sentinel or CDC traps can potentially improve the efficacy of Ae. albopictus and Cx. quinquefasciatus mosquito surveillance. Moreover, when using Mix-5, specialized equipment is not required to carry the chemicals, thereby avoiding traditional methods for $\mathrm{CO}_{2}$ delivery, thus saving material cost and labor. Notably, other cues such as moisture, heat and visual cues also affect the recognition of hosts by mosquitoes [27, 42], and different habitats may be suitable for different mosquito species, which may partially explain why different types of sites had different effects. Different dispensing methods should also be tested in future studies.

It should be noted that BG-Lure, although not the most efficient bait, is widely used with consistent results across multiple settings. In this study, we found that the Mix-5 lure was significantly more efficient in attracting $A e$. albopictus relative to control treatment in the laboratory setting, and Mix-5 was slightly more efficient than BGLure in the field setting. However, whether Mix-5 is consistently more efficient than BG-Lure in different settings needs to be further investigated. Furthermore, BG-Lure is good for attracting different species of mosquitoes, for example Ae. aegypti, Ae. albopictus and Culex pipiens mosquitoes, but whether Mix-5 is a good lure for $A e$. aegypti and Culex pipiens mosquitoes would be a subject for further investigation.

\section{Conclusions}

We developed and evaluated a human odor-based attractant blend that enhanced the effectiveness of attracting adult Ae. albopictus mosquitoes. Exploiting the behavioral responses of different types of mosquito chemoreceptors to host stimuli provides new paradigms for the development of new surveillance and control tools for major disease vectors.

\section{Additional files}

Additional file 1: Table S1. List of odorants used in the experiments against Ae. albopictus females.

Additional file 2: Table S2. The molecular structure and activated receptor of each odorant.

Additional file 3: Table S3. The orthogonal design list.

Additional file 4: Figure S1. The estimated marginal means of a 1-octen3-ol and b 6-methyl-5-hepten-2-one.

\section{Abbreviations}

BGS: Biogents Sentinel trap; ORs: odorant receptors; IRs: ionotropic receptors; GRs: gustatory receptors; GR3: gustatory receptor 3; OR8: odorant receptor8; OR4: odorant receptor4; $\mathrm{C}_{5} \mathrm{H}_{8} \mathrm{O}$ : cyclopentanone; $\mathrm{cpA}$ : $\mathrm{CO}_{2}$-responsive neurons.

\section{Acknowledgements}

The authors would like to thank colleagues from Southern Medical University who provided advice, helped with experiments and provided valuable support.

\section{Authors' contributions}

All authors contributed significantly to this study. XC, GY and LX conceived the study and coordinated its implementation. XC, GY, HL and LX participated in the experimental design. $L X, W Y, T L, Y X, F L, J G, X Z$ and $K W$ performed the experiments and drafted the manuscript, which was critically revised by GZ and XC. All authors read and approved the final manuscript. 


\section{Funding}

This research was supported by a combination of funding from the National Nature Science Foundation of China (81420108024, 31830087, 81829004), the National Institutes of Health, USA (Al136850), the Natural Science Foundation of Guangdong Province (2014A030312016), and the Guangzhou Synergy Innovation Key Program for Health (201807010005, 201803040006).

\section{Availability of data and materials}

The datasets supporting the conclusions of this article are included within the article and its additional files.

\section{Ethics approval and consent to participate}

Not applicable. No specific permits were required for our experiment. This study did not involve endangered or protected species.

\section{Consent for publication}

Not applicable.

\section{Competing interests}

The authors declare that they have no competing interests.

\section{Author details}

${ }^{1}$ Department of Pathogen Biology, Guangdong Provincial Key Laboratory of Tropical Disease Research, School of Public Health, Southern Medical University, Guangzhou, China. ${ }^{2}$ Program in Public Health, University of California Irvine, Irvine, California, USA.

Received: 5 March 2019 Accepted: 25 July 2019

Published online: 30 July 2019

\section{References}

1. Enserink M. A mosquito goes global. Science. 2008;320:3.

2. Smallegange RC, Qiu YT, van Loon JJ, Takken W. Synergism between ammonia, lactic acid and carboxylic acids as kairomones in the hostseeking behaviour of the malaria mosquito Anopheles gambiae sensu stricto (Diptera: Culicidae). Chem Senses. 2005;30:145-52.

3. Krockel U, Rose A, Eiras AE, Geier M. New tools for surveillance of adult yellow fever mosquitoes: Comparison of trap catches with human landing rates in an urban environment. J Am Mosq Control Assoc. 2006;22:229-38.

4. Roiz D, Duperier S, Roussel M, Bousses P, Fontenille D, Simard F, et al. Trapping the tiger: efficacy of the novel BG-Sentinel 2 with several attractants and carbon dioxide for collecting Aedes albopictus (Diptera: Culicidae) in Southern France. J Med Entomol. 2016;53:460-5.

5. Li Y, Su X, Zhou G, Zhang H, Puthiyakunnon S, Shuai S, et al. Comparative evaluation of the efficiency of the BG-Sentinel trap, CDC light trap and mosquito-oviposition trap for the surveillance of vector mosquitoes. Parasit Vectors. 2016;9:446

6. Bernier UR, Kline DL, Barnard DR, Schreck CE, Yost RA. Analysis of human skin emanations by gas chromatography/mass spectrometry. 2. Identification of volatile compounds that are candidate attractants for the yellow fever mosquito (Aedes aegypti). Anal Chem. 2000;72:747-56.

7. Pandey SK, Kim K-H. Human body-odor components and their determination. TrAC Trends Anal Chem. 2011;30:784-96.

8. Smallegange RC, Verhulst NO, Takken W. Sweaty skin: an invitation to bite? Trends Parasitol. 2011;27:143-8.

9. Pombi M, Jacobs F, Verhulst NO, Caputo B, della Torre A, Takken W. Field evaluation of a novel synthetic odour blend and of the synergistic role of carbon dioxide for sampling host-seeking Aedes albopictus adults in Rome, Italy. Parasit Vectors. 2014;7:580.

10. Mathew N, Ayyanar E, Shanmugavelu S, Muthuswamy K. Mosquito attractant blends to trap host seeking Aedes aegypti. Parasitol Res. 2013;112:1305-12.

11. Okumu FO, Killeen GF, Ogoma S, Biswaro L, Smallegange RC, Mbeyela E, et al. Development and field evaluation of a synthetic mosquito lure that is more attractive than humans. PLoS ONE. 2010;5:e8951.

12. Silva IM, Eiras AE, Kline DL, Bernier UR. Laboratory evaluation of mosquito traps baited with a synthetic human odor blend to capture Aedes aegypti. J Am Mosq Control Assoc. 2005;21:229-33.
13. Tauxe GM, MacWilliam D, Boyle SM, Guda T, Ray A. Targeting a dual detector of skin and $\mathrm{CO}_{2}$ to modify mosquito host seeking. Cell. 2013:155:1365-79.

14. Philippe-Janon JC, van den Hurk AF, Francis DP, Shivas MA, Jansen CC. Field comparison of cyclopentanone versus carbon dioxide as an attractant for adult mosquitoes in southeast Queensland, Australia. J Med Entomol. 2015;52:483-90.

15. Verhulst NO, Beijleveld H, Knols BG, Takken W, Schraa G, Bouwmeester $\mathrm{HJ}$, et al. Cultured skin microbiota attracts malaria mosquitoes. Malar J. 2009;8:302.

16. Beavers GM, Hanafi HA, Tetreault GE. Response of mosquitoes (Diptera: Culicidae) to carbon dioxide and octenol in Egypt. J Egypt Soc Parasitol. 1998;28:303-12.

17. Bosch OJ, Geier M, Boeckh J. Contribution of fatty acids to olfactory host finding of female Aedes aegypti. Chem Senses. 2000;25:8.

18. Rueda LM, Harrison BA, Brown JS, Whitt PB, Harrison RL, Gardner RC. Evaluation of 1-octen-3-ol, carbon dioxide, and light as attractants for mosquitoes associated with two distinct habitats in North Carolina. J Am Mosq Control Assoc. 2001;17:61-6.

19. Bernier UR, Kline DL, Posey KH, Booth MM, Yost RA, Barnard DR. Synergistic attraction of Aedes aegypti (L.) to binary blends of L-lactic acid and acetone, dichloromethane, or dimethyl disulfide. J Med Entomol. 2003;40:653-6

20. Verhulst NO, Mukabana WR, Takken W, Smallegange RC. Human skin microbiota and their volatiles as odour baits for the malaria mosquito Anopheles gambiae s.s. Entomol Exp Appl. 2011;139:170-9.

21. Davis EE, Sokolove PG. Lactic acid-sensitive receptors on the antennae of the mosquito, Aedes aegypti. J Comp Physiol. 1976;105:43-54

22. Silbering AF, Rytz R, Grosjean $Y$, Abuin L, Ramdya P, Jefferis GS, et al. Complementary function and integrated wiring of the evolutionarily distinct Drosophila olfactory subsystems. J Neurosci. 2011;31:13357-75.

23. Rytz R, Croset V, Benton R. Ionotropic receptors (IRs): chemosensory ionotropic glutamate receptors in Drosophila and beyond. Insect Biochem Mol Biol. 2013;43:888-97.

24. Carey AF, Wang G, Su CY, Zwiebel LJ, Carlson JR. Odorant reception in the malaria mosquito Anopheles gambiae. Nature. 2010;464:66-71.

25. McBride CS, Baier F, Omondi AB, Spitzer SA, Lutomiah J, Sang R, et al. Evolution of mosquito preference for humans linked to an odorant receptor. Nature. 2014;515:222-7.

26. Qiu YT, van Loon JJ, Takken W, Meijerink J, Smid HM. Olfactory coding in antennal neurons of the malaria mosquito, Anopheles gambiae. Chem Senses. 2006:31:845-63.

27. McMeniman CJ, Corfas RA, Matthews BJ, Ritchie SA, Vosshall LB. Multimodal integration of carbon dioxide and other sensory cues drives mosquito attraction to humans. Cell. 2014;156:1060-71.

28. Geier M, Boeckh J. A new Y-tube olfactometer for mosquitoes to measure the attractiveness of host odours. Entomol Exp Appl. 1999;92:9-19.

29. Mukabana WR, Takken W, Coe R, Knols BG. Host-specific cues cause differential attractiveness of Kenyan men to the African malaria vector Anopheles gambiae. Malar J. 2002;1:17.

30. Pettersson J. An aphid sex attractant. Insect Syst Evol. 1971;2:63-73.

31. Lin L, Lu W, Cai S, Duan J, Yi J, Deng F, et al. The design and efficacy observation of new mosq-ovitrap for monitoring of vector of dengue fever. Chinese J Vector Biol Control. 2005;16:26-8.

32. Farajollahi A, Kesavaraju B, Price DC, Williams GM, Healy SP, Gaugler R, et al. Field efficacy of BG-Sentinel and industry-standard traps for Aedes albopictus (Diptera: Culicidae) and West Nile virus surveillance. J Med Entomol. 2009;46:919-25.

33. Rochlin I, Kawalkowski M, Ninivaggi DV. Comparison of mosquito magnet and Biogents Sentinel traps for operational surveillance of container-inhabiting Aedes (Diptera: Culicidae) species. J Med Entomol. 2016:53:454-9.

34. Okumu F, Biswaro L, Mbeleyela E, Killeen GF, Mukabana R, Moore SJ. Using nylon strips to dispense mosquito attractants for sampling the malaria vector Anopheles gambiae s.s. J Med Entomol. 2010;47:274-82.

35. Dong $X$, Zhou H, Gong Z. The mosquito fauna of Yunnan. Kunming: Yunnan Publishing Group; 2010. p. 394.

36. Owino EA, Sang R, Sole CL, Pirk C, Mbogo C, Torto B. An improved odor bait for monitoring populations of Aedes aegypti-vectors of dengue and chikungunya viruses in Kenya. Parasit Vectors. 2015;8:253. 
37. Mukabana WR, Mweresa CK, Otieno B, Omusula P, Smallegange RC, van Loon JJ, et al. A novel synthetic odorant blend for trapping of malaria and other African mosquito species. J Chem Ecol. 2012;38:235-44.

38. Bernier UR, Kline DL, Schreck CE, Yost RA, Barnard DR. Chemical analysis of human skin emanations: comparison of volatiles from humans that differ in attraction of Aedes aegypti (Diptera: Culicidae). J Am Mosq Control Assoc. 2002;18:186-95.

39. Logan JG, Birkett MA, Clark SJ, Powers S, Seal NJ, Wadhams LJ, et al. Identification of human-derived volatile chemicals that interfere with attraction of Aedes aegypti mosquitoes. J Chem Ecol. 2008;34:308-22.

40. Kundu S, Ganguly A, Chakraborty TS, Kumar A, Siddiqi O. Synergism and combinatorial coding for binary odor mixture perception in Drosophila. eNeuro. 2016;3:27588303.
41. Englbrecht C, Gordon S, Venturelli C, Rose A, Geier M. Evaluation of BG-Sentinel trap as a management tool to reduce Aedes albopictus nuisance in an urban rnvironment in Italy. J Am Mosq Control Assoc. 2015;31:16-25.

42. Zwiebel LJ, Takken W. Olfactory regulation of mosquito-host interactions. Insect Biochem Mol Biol. 2004;34:645-52.

\section{Publisher's Note}

Springer Nature remains neutral with regard to jurisdictional claims in published maps and institutional affiliations.
Ready to submit your research? Choose BMC and benefit from:

- fast, convenient online submission

- thorough peer review by experienced researchers in your field

- rapid publication on acceptance

- support for research data, including large and complex data types

- gold Open Access which fosters wider collaboration and increased citations

- maximum visibility for your research: over $100 \mathrm{M}$ website views per year

At BMC, research is always in progress.

Learn more biomedcentral.com/submissions 